\title{
Free Vibration Analysis of Composite Beams with Overlapping Delaminations under Axial Compressive Loading
}

\author{
Christian N. Della* \\ School of Engineering, University of Glasgow, G12 8QQ, UK
}

\begin{abstract}
Analytical solutions have been developed to study the free vibrations of composite beams with two overlapping delaminations under axial compressive load. The delaminated beam is analyzed as seven Euler-Bernoulli beams connected at the delamination boundaries. The continuity and equilibrium conditions are satisfied between the adjoining regions of the beams. Lower and upper bounds of the natural frequencies of the delaminated beams are identified by assuming totally 'free' and totally 'constrained' deformations of the delaminated layers, respectively. These solutions can serve as generalized solutions for vibration and buckling of delaminated composites. The relation between the square of the natural frequency of the delaminated beam and the axial compressive load is also investigated. Results show a linear relation between the square of the "constrained mode" and "free mode" frequencies of the simply supported beam and the axial compressive load. A non-linear relation is observed between the square of the "free mode" frequencies of a clamped-clamped beam and axial compressive load due to the opening of the delaminated layers in the "free mode" mode shape of the beam.
\end{abstract}

Keywords: Delamination; Vibration; Compressive load; Buckling; Composite beams

*E-mail: Christian.Della@glasgow.ac.uk

Present Address: University of Glasgow Singapore

Level 4 SIT Building, 537 Clementi Road, Ngee Ann Polytechnic

Singapore 599493

Tel: 65-69086203; FAX: 65-69086208 


\section{Introduction}

Delamination is a common failure mode in layered structures. It may arise due to the loss of adhesion between two layers of the structure, interlaminar stresses arising from geometric or material discontinuities, or mechanical loadings (e.g. compression, impact, vibration, fatigue loadings). The presence of delamination may significantly reduce the stiffness and strength of the structures, which will influence the vibration characteristics and load carrying capacity of the structures.

Many analytical models have been reported to study the vibration of delaminated composite laminates [1]. The 'free mode' model by Wang et al. [2] and the 'constrained mode' model by Mujumdar and Suryanarayan [3] are among the earliest models presented to study the vibration of delaminated beams. The 'free mode' model assumes that the delaminated layers vibrate 'freely' and will have different transverse deformations, whereas, the 'constrained mode' model assumes that the delaminated layers are 'constrained' to have identical transverse deformations but are free to slide over each other in the axial direction except at their ends. To address both assumptions, as well the opening in the modeshapes found in experiments by Shen and Grady [4], Luo and Hanagud [5] presented an analytical model using the Timoshenko beam theory and piecewise-linear springs, where the spring stiffness between the delaminated layers would then be equal to zero $(0)$ for the 'free mode' and infinity $(\infty)$ for the 'constrained mode'.

Studies on buckling of delaminated composites have been presented by many researchers. Huang and Kardomateas [6] presented an analytical solution based on the 'free mode' assumption for the buckling of beam-plates with two delaminations. This was used to study the effects of the delamination sizes and locations on the buckling load of the beam-plates. Lim and Parsons [7] studied the buckling of beams with two fully 
overlapping delaminations (double delaminations) by using the energy method and the 'free mode' assumption. S-shaped buckling modes or second buckling modes were observed for certain delamination lengths when two delaminated layers are of equal thickness. Shu [8] developed an exact solution to study the buckling of beams with double delaminations. A comparison between the results of the energy method and exact solution showed that higher buckling loads were obtained by using the exact solution in cases when S-shaped buckling modes occurs. However, the results of the exact solution only displayed single-hump modes or first buckling mode rather than the S-shaped mode.

Many works have been presented for buckling of beams and plates with multiple delaminations [6-14]. However, most of these works focused mainly on the use of the "free mode" assumption. Few works have considered both the "free mode" and "constrained mode" assumptions in their work. Wang et al. [10] used the 'free mode' and the 'constrained mode' assumptions to study the buckling of multiple delaminated beams. These two assumptions have also been used for a beam with two nonoverlapping delaminations [13] and two enveloped delaminations [14], where the "free mode" and "constrained mode" assumptions were used as lower bound and upper bound solutions, respectively.

Similarly, many works have been presented to study the vibration of multipledelaminated composite laminates [1, 15-23]. Shu [15] presented an analytical solution for a sandwich beam with double delaminations. His study emphasized on the influence of the contact mode, 'free' and 'constrained', between the delaminated layers and the local deformation at the delamination fronts. Della and Shu [16] further investigated a beam with double delaminations by using the 'free mode', the 'partially constrained mode' and the 'constrained mode' assumption. Lestari and Hanagud [17] developed an analytical model by using the Euler-Bernoulli beam theory and piecewise-linear springs to study a 
composite beam with multiple delaminations. Lee et al. [18] studied a composite beam with arbitrary lateral and longitudinal multiple delaminations by using the 'free mode' assumption. Shu and Della $[19,20]$ and Della and Shu [21] developed analytical solutions using the 'free mode' and 'constrained mode' assumptions to study composite beams with multiple delaminations. Their study emphasized on the influence of a second short delamination on the first mode and second mode bending frequencies and the corresponding mode shapes of the beam.

Relatively few works for the vibration of delaminated composite laminates relative to their buckled states have been reported in the literature. Chen [24] developed analytical solutions for the free vibration of isotropic beam-plates with a single symmetric delamination in the prebuckled and postbuckled states. The 'constrained mode' assumption was used for prebuckling conditions, whereas, the 'free mode' assumption was used for the postbuckling conditions. Chen et al. [25] developed an analytical model to study the vibration of prebuckled composite beam with arbitrary delamination location by using the classical laminate theory and the 'constrained mode' assumption, which have been validated with experimental data. Chang et al. [26] presented a model using an elastic foundation analysis. The delaminated plate was treated as a plate on a continuously distributed support, but with added transverse forces in the delamination region. The elastic foundation was represented by an infinite set of parallel springs with no shear coupling between them.

Yin and Jane [27] presented an analytical solution using the 'free mode' assumption for the vibration of postbuckled isotropic beam with a delamination located symmetrically about the beam center, which was extended by Jane and Chen [28] for delaminated beam-plates with arbitrary delamination location. Chang and Liang [29] presented an analytical solution for postbuckled delaminated isotropic beam-plates. Based 
on the revised boundary conditions and governing partial differential equations, the natural frequencies and mode shapes of the postbuckled delaminated beam-plates were determined by using separation of variables. The above models [27-29] neglected the transverse shear deformation effect, which was found to have a significant influence on the buckling load and the post-buckling deformation by Chen [24] and Chen and Goggin [30].

Lu and Hanagud [31] presented an analytical solution for composite beams with two delaminations subjected under axial compressive load. The 'free mode' assumption and the Timoshenko beam theory were used. Their results showed that the natural frequency and the mode shape were significantly affected by long and thin delaminations. Lee et al. [32] presented an analytical method for composite beam-columns with multiple delaminations. The 'free mode' assumption and the Euler-Bernoulli beam theory were used. Experiments were conducted to validate the results of the analytical model. Jane and Harn [33] presented approximate solutions by using the 'constrained mode' assumption for beams with multiple delaminations. A series solution to the governing equations of motion was used for simply supported beams, whereas, the Ritz method was used for clamped-clamped beams. Della and Shu [34,35] presented analytical solutions for isotropic beams with two overlapping delaminations [34] and enveloped delaminations [35] by using both the "free mode" and "constrained mode" assumptions.

Earlier studies by Amba-Rao [36] and Galef [37] on the free vibration of axially compressed undelaminated beam showed that for a simply supported beam, the linear relation between the natural frequency and the axial compressive load can be expressed as

$$
\left(\omega / \omega_{0}\right)^{2}=1-P_{1}^{0} / P_{c r}
$$

where $\omega$ is the natural frequency of the axially compressed beam, $\omega_{0}$ is the natural frequency of beam without compressive loading, $P_{1}^{0}$ is the axial compressive load and 
$P_{c r}$ is the buckling load of the beam. The natural frequency vanishes $(\omega=0.0)$ when the axial load $P_{1}^{0} / P_{c r}$ is equal to the normalized buckling load. Further study by Bokaian [38] showed that this relation is applicable to other beam-columns with either simply supported or sliding end condition and can roughly describe the variation for clampedclamped beams.

Based on the above literature survey, a study on the vibration of axially compressed composite beams with two overlapping delaminations has not been presented in the literature, and the relationship between the square of the natural frequency of the delaminated beam and its buckling load has not been fully understood. In this research, analytical solutions are developed to study the free vibration of composite beams with two-overlapping delaminations under axial compressive loading. The lower bound and the upper bound solution are identified by assuming totally 'free' and totally 'constrained' deformations of the delaminated layers, respectively. These two bounds can be useful to gauge the working range of the natural frequencies of the delaminated beam and provide guidelines for practical applications. The present analytical solutions can also be used to for pure buckling or vibration analysis. In addition, the linear relation between the square of the natural frequencies of the simply supported and clamped-clamped delaminated beams and the axial compressive loading are investigated.

The research is presented as follows. Firstly, the vibration of a composite beam with two overlapping delaminations under axial compressive loading is formulated. Secondly, the present results are verified with the published analytical results on the vibration and buckling of delaminated beams. Finally, the vibration of the delaminated composites beams under axial compressive loading is studied. 


\section{Formulation}

In this section the analytical solution to the vibration of prebuckled beams with two overlapping delamination is formulated. Fig. 1 shows a beam with length $L$ and thickness $H_{1}$ with two overlapping delaminations. The upper and the lower delamination have the lengths of $a_{1}$ and $a_{2}$, respectively, and located at distances $d_{1}$ and $d_{2}$ away from the center of the beam, respectively. The delaminated beam is analyzed as seven beams connected at the delamination boundaries. The two delaminations divide the beam into three layers with thickness $H_{3}, H_{4}$ and $H_{5}$. The Euler-Bernoulli beam theory is used to analyze each of the beams and both the 'free mode' and the 'constrained mode' assumption are used.

\section{1. 'Free mode'}

The governing equations for the free vibrations of a delaminated beam under axial compressive loading using the Euler-Bernoulli beam theory are

$$
D_{i} \frac{\partial^{4} w_{i}}{\partial x^{4}}+\rho_{i} A_{i} \frac{\partial^{2} w_{i}}{\partial t^{2}}+P_{i}^{0} \frac{\partial^{2} w_{i}}{\partial x^{2}}=0 \quad(i=1-7)
$$

where $D_{i}(i=1-7)$ is the bending stiffness of beam $i, w_{i}(x, t)$ is the midplane deflection of beam $i, \rho_{i}$ is the mass density, $A_{i}$ is the cross-sectional area of the beam, $P_{i}^{0}$ is the axial compressive force at the static prebuckled state and $P_{1}^{0}=P_{2}^{0}+P_{3}^{0}=P_{4}^{0}+P_{6}^{0}, P_{2}^{0}=P_{4}^{0}+P_{5}^{0}$ and $P_{6}^{0}=P_{3}^{0}+P_{5}^{0}$. The mechanical properties of the composite beams are determined using the classical laminate theory [39] and are given as

$$
A_{i}=A_{11}^{(i)}=b \sum_{k=1}^{n_{i}}\left(\bar{Q}_{11}^{k}\right)_{k}\left(z_{k}-z_{k-1}\right)
$$




$$
\begin{aligned}
& D_{i}=D_{11}^{(i)}=\frac{b}{3} \sum_{k=1}^{n_{i}}\left(\bar{Q}_{11}^{k}\right)_{k}\left(z_{k}^{3}-z_{k-1}^{3}\right) \\
& \bar{Q}_{11}^{k}=Q_{11}^{k} \cos ^{4} \phi+Q_{22}^{k} \sin ^{4} \phi+2\left(Q_{12}^{k}+2 Q_{66}^{k}\right) \cos ^{2} \phi \sin ^{2} \phi \\
& Q_{11}=\frac{E_{11}}{1-v_{12} v_{21}} \\
& Q_{22}=\frac{E_{22}}{1-v_{12} v_{21}} \\
& Q_{12}=\frac{v_{12} E_{22}}{1-v_{12} v_{21}}=\frac{v_{21} E_{11}}{1-v_{12} v_{21}} \\
& Q_{66}=G_{12} \\
& v_{21}=\frac{v_{12} E_{22}}{E_{11}}
\end{aligned}
$$

and where $A_{11}^{(i)}$ is the extensional stiffness, $D_{11}^{(i)}$ is the bending stiffness, $\bar{Q}_{11}^{k}$ is the coefficient stiffness of the lamina, $b$ is the width, $n_{i}$ is the number of plies, $E_{11}$ and $E_{22}$ are the longitudinal and transverse Young's moduli, respectively, $G_{12}$ is the in-plane shear modulus, $v_{12}$ and $v_{21}$ are the longitudinal and transverse Poisson's ratio, respectively, $\phi$ is the angle of the $k$-th lamina orientation and $z_{k}$ and $z_{k-1}$ are the locations of the $k$-th lamina with respect to the midplane of the $i$-th beam, as shown in Fig. 2.

Substituting $w_{i}\left(x_{i}, t\right)=W_{i}\left(x_{i}\right) \sin (\omega t)$ for free vibration in Eq. (2), and eliminating the trivial solution $\sin (\omega t)=0$, it follows that

$$
D_{i} W_{i}{ }^{\prime \prime \prime}+P_{i}^{0} W_{i} "-\rho_{i} A_{i} \omega^{2} W_{i}=0 \quad(i=1-7)
$$

where $\omega$ is the natural frequency, $W_{i}$ is the mode shape and prime (') denotes differentiation with respect to the $x$-coordinate. The generalized solutions for the differential equation in Eq. (4) are 


$$
W_{i}(x)=C_{i} \cos \left(\alpha_{i} \frac{x}{L}\right)+S_{i} \sin \left(\alpha_{i} \frac{x}{L}\right)+C H_{i} \cosh \left(\beta_{i} \frac{x}{L}\right)+S H_{i} \sinh \left(\beta_{i} \frac{x}{L}\right)
$$

where

$$
\begin{aligned}
& \alpha_{i}^{2}=\frac{P_{i}^{0}+\sqrt{\left(P_{i}^{0}\right)^{2}+4 \rho_{i} A_{i} D_{i} \omega^{2}}}{2 D_{i}} L^{2} \\
& \beta_{i}^{2}=\frac{-P_{i}^{0}+\sqrt{\left(P_{i}^{0}\right)^{2}+4 \rho_{i} A_{i} D_{i} \omega^{2}}}{2 D_{i}} L^{2}
\end{aligned}
$$

By applying the 4 boundary conditions and the 24 continuity conditions, the 28 unknown coefficients $\mathrm{C}_{i}, \mathrm{~S}_{i}, \mathrm{CH}_{i}$ and $\mathrm{SH}_{i}$ can be determined.

The appropriate boundary conditions that can be applied at the supports, $x=x_{1}$ and $x=x_{4}$, are $W_{i}=0$ and $W_{i}{ }^{\prime}=0$, if the end of the beam is clamped; $W_{i}=0$ and $W_{i}{ }^{\prime \prime}=0$, if simply supported where $i=1$ and 7 .

The continuity conditions for deflection and slope at the delamination boundary $x=x_{2}$ are

$$
\begin{aligned}
& W_{1}=W_{2}=W_{3} \\
& W_{1}{ }^{\prime}=W_{2}{ }^{\prime}=W_{3}{ }^{\prime}
\end{aligned}
$$

The continuity for shear and bending moments at the delamination boundary $x=x_{2}$ are

$$
\begin{aligned}
& D_{1} W_{1} " '=D_{2} W_{2} " '+D_{3} W_{3} " ' \\
& D_{1} W_{1} "=D_{2} W_{2} "+D_{3} W_{3} "+P_{2}\left(\frac{H_{1}}{2}-\frac{H_{2}}{2}\right)-P_{3}\left(\frac{H_{1}}{2}-\frac{H_{3}}{2}\right)
\end{aligned}
$$

Each of the delamination boundaries $x=x_{3}, x=x_{4}$ and $x=x_{5}$ provides 6 equations and a total of 24 equations can be set up for all the delamination boundaries. Five axial forces $P_{2}, P_{3}, P_{4}, P_{5}$ and $P_{6}$ that appear in the moment continuity condition are still unknown, so additional five equations are needed. At $x=x_{2}$ and $x=x_{5}$, from the axial force balance, we have 


$$
\begin{aligned}
& P_{1}=P_{2}+P_{3}=0 \\
& P_{7}=P_{4}+P_{6}=0
\end{aligned}
$$

At $x=x_{3}$ and $x=x_{4}$, from the axial force balance, we have

$$
\begin{aligned}
& P_{2}=P_{4}+P_{5} \\
& P_{6}=P_{3}+P_{5}
\end{aligned}
$$

If the beam does not vibrate, $P_{2}, P_{3}, P_{4}, P_{5}$ and $P_{6}$ are all zero, because they are defined as the axial forces present during the vibration of the beam. The axial length of the beam between $x=x_{2}$ and $x=x_{5}$ remains equal before and during vibration (Fig. 3). This leads to the following equations.

$$
\begin{aligned}
\left(\frac{H_{1}}{2}-\frac{H_{2}}{2}\right) W_{1}{ }^{\prime}\left(x_{2}\right)+L_{2} & +\left(\frac{H_{2}}{2}-\frac{H_{4}}{2}\right) W_{2}{ }^{\prime}\left(x_{3}\right)+L_{4}-\left(\frac{H_{7}}{2}-\frac{H_{4}}{2}\right) W_{7}{ }^{\prime}\left(x_{5}\right)=L_{2 o}+L_{4 o} \\
\left(\frac{H_{1}}{2}-\frac{H_{2}}{2}\right) W_{1}^{\prime}\left(x_{2}\right)+L_{2} & +\left(\frac{H_{5}}{2}-\frac{H_{2}}{2}\right) W_{2}^{\prime}\left(x_{3}\right)+L_{5}-\left(\frac{H_{6}}{2}-\frac{H_{5}}{2}\right) W_{6}{ }^{\prime}\left(x_{4}\right) \\
& +L_{6}-\left(\frac{H_{6}}{2}-\frac{H_{7}}{2}\right) W_{7}{ }^{\prime}\left(x_{5}\right)=L_{2 o}+L_{5 o}+L_{6 o} \\
\left(\frac{H_{3}}{2}-\frac{H_{1}}{2}\right) W_{1}{ }^{\prime}\left(x_{2}\right)+L_{3}- & \left(\frac{H_{3}}{2}-\frac{H_{6}}{2}\right) W_{6}^{\prime}\left(x_{4}\right)+L_{6}-\left(\frac{H_{6}}{2}-\frac{H}{2}\right) W_{7}{ }^{\prime}\left(x_{5}\right)=L_{3 o}+L_{6 o}
\end{aligned}
$$

where $L_{i o}$ represents the length of the $i$ th beam segment before vibration and $H_{i}$ is the thickness of the $i$ th beam segment. If we let $L_{i}$ represent the deformed length of the $i$ th beam segment, then we have

$$
L_{i}-L_{i o}=\frac{P_{i} L_{i o}}{A_{11}^{(i)}} \quad(i=2-6)
$$

Substituting Eq. (19) into Eqs. (16) to (18) leads to

$$
\frac{P_{2} L_{2 o}}{A_{11}^{(2)}}+\frac{P_{4} L_{4 o}}{A_{11}^{(4)}}=-\left(\frac{H_{1}}{2}-\frac{H_{2}}{2}\right) W_{1}{ }^{\prime}\left(x_{2}\right)-\left(\frac{H_{2}}{2}-\frac{H_{4}}{2}\right) W_{2}{ }^{\prime}\left(x_{3}\right)+\left(\frac{H_{7}}{2}-\frac{H_{4}}{2}\right) W_{7}{ }^{\prime}\left(x_{5}\right)
$$




$$
\begin{aligned}
& \frac{P_{2} L_{2 o}}{A_{11}^{(2)}}+\frac{P_{5} L_{5 o}}{A_{11}^{(5)}}+\frac{P_{6} L_{6 o}}{A_{11}^{(6)}}=-\left(\frac{H_{1}}{2}-\frac{H_{2}}{2}\right) W_{1}{ }^{\prime}\left(x_{2}\right)-\left(\frac{H_{5}}{2}-\frac{H_{2}}{2}\right) W_{2}{ }^{\prime}\left(x_{3}\right) \\
&+\left(\frac{H_{6}}{2}-\frac{H_{5}}{2}\right) W_{6}{ }^{\prime}\left(x_{4}\right)+\left(\frac{H_{6}}{2}-\frac{H_{7}}{2}\right) W_{7}{ }^{\prime}\left(x_{5}\right) \\
& \frac{P_{3} L_{3 o}}{A_{11}^{(3)}}+\frac{P_{6} L_{6 o}}{A_{11}^{(6)}}=-\left(\frac{H_{3}}{2}-\frac{H_{1}}{2}\right) W_{1}{ }^{\prime}\left(x_{2}\right)+\left(\frac{H_{3}}{2}-\frac{H_{6}}{2}\right) W_{6}{ }^{\prime}\left(x_{4}\right)+\left(\frac{H_{6}}{2}-\frac{H_{7}}{2}\right) W_{7}{ }^{\prime}\left(x_{5}\right)
\end{aligned}
$$

The total number of boundary and continuity conditions is 28 , which is equal to the total number of unknown coefficients $C_{i}, S_{i}, C H_{i}$ and $S_{i}$. A non-trivial solution exists only when the determinant of the coefficient matrix vanishes. The natural frequencies can be obtained as eigenvalues and the mode shapes, as eigenvectors.

\section{2. 'Constrained mode'}

The 'constrained mode' analysis is simplified by the assumption that the delaminated layers are 'constrained' to have the same transverse deformations. The delaminated beam is analyzed as five beam segments I - V (Fig. 1). The governing equations are

$$
D_{i} \frac{\partial^{4} w_{i}}{\partial x^{4}}+\rho_{i} A_{i} \frac{\partial^{2} w_{i}}{\partial t^{2}}+P_{1}^{0} \frac{\partial^{2} w_{i}}{\partial x^{2}}=0 \quad(i=\mathrm{I}-\mathrm{V})
$$

where

$$
\begin{aligned}
& D_{I}=D_{V} \\
& D_{I I}=D_{2}+D_{3} \\
& D_{I I I}=D_{3}+D_{4}+D_{5} \\
& D_{I V}=D_{4}+D_{6} \\
& \rho_{I} A_{I}=\rho_{V} A_{V}=\rho_{1} A_{1} \\
& \rho_{I I} A_{I I}=\rho_{2} A_{2}+\rho_{3} A_{3} \\
& \rho_{I I} A_{I I I}=\rho_{3} A_{3}+\rho_{4} A_{4}+\rho_{5} A_{5}
\end{aligned}
$$




$$
\rho_{I V} A_{I V}=\rho_{4} A_{4}+\rho_{6} A_{6}
$$

The generalized solutions for the 'constrained mode' are identical in form to the 'free mode'. The unknown coefficients $C_{i}, S_{i}, C H_{i}$ and $S H_{i}$, however, are reduced to 20 coefficients which can be determined from the 4 boundary conditions and the 16 continuity conditions.

The boundary conditions for the 'constrained mode' are identical to the boundary conditions of the 'free mode'. The continuity conditions for deflection, slope, shear and bending moments at $x=x_{2}$ are,

$$
\begin{aligned}
& W_{I}=W_{I I} \\
& W_{I}{ }^{\prime}=W_{I I}{ }^{\prime} \\
& D_{I} W_{I}{ }^{\prime \prime}=D_{I I} W_{I I}{ }^{\prime \prime} \\
& D_{I} W_{I}{ }^{\prime \prime}=D_{I I} W_{I I}{ }^{\prime}+P_{2}\left(\frac{H_{1}}{2}-\frac{H_{2}}{2}\right)-P_{3}\left(\frac{H_{1}}{2}-\frac{H_{3}}{2}\right)
\end{aligned}
$$

Similarly, we can derive the continuity conditions at $x=x_{3}, x=x_{4}$ and $x=x_{5}$. For the 'constrained mode', the boundary and continuity conditions provide 20 homogeneous equations for 20 unknown coefficients $C_{i}, S_{i}, \mathrm{CH}_{i}$ and $S H_{i}$.

\subsection{Lower bound and upper bound of the natural frequency}

In the present research, the delaminated layers, beams $2-6$, are assumed to vibrate independently ('free mode') or vibrate together ('constrained mode'). In general, a delaminated layer maybe constrained by another layer. Lou and Hanagud [5] and Lestari and Hanagud [7] presented analytical models using piecewise-linear springs to simulate the 'open' and 'closed' behavior between the delaminated layers. The spring stiffness would then be equal to zero (0) for the 'free mode' and infinity $(\infty)$ for the 'constrained mode'. However, such analysis is tedious and complex. For multiple delaminations, the 
solution will be very lengthy and the order of complexity will render an exact solution impossible. In the present research, we propose to estimate the lower bound and upper bound of the natural frequency by using the 'free mode' and 'constrained mode', respectively. The accuracy of such approximations, however, needs to be further studied through experiments or numerical schemes.

\section{Results and Discussions}

\subsection{Verification 1: Vibration of a cantilever beam with a single delamination}

To verify the accuracy of the present analytical solutions on vibration of delaminated beams, a comparison is made with published results on a cantilever composite beam single delamination, which was studied by Shen and Grady [4] The beam is made of T300/934 graphite/epoxy cantilever beam with a $\left[0^{\circ} / 90^{\circ}\right]_{2 s}$ stacking sequence. The dimensions of the 8-ply beam are $127 \times 12.7 \times 1.016 \mathrm{~mm}^{3}$. The material properties for the lamina are: $E_{11}=134 \mathrm{GPa}, E_{22}=10.3 \mathrm{GPa}, G_{12}=5 \mathrm{GPa}, v_{12}=0.33$ and $\rho=1.48 \mathrm{X}$ $10^{3} \mathrm{~kg} / \mathrm{m}^{3}$. All the delaminations are at midspan and the lengths are $25.4 \mathrm{~mm}, 50.8 \mathrm{~mm}$, $76.2 \mathrm{~mm}$ and $101.6 \mathrm{~mm}$. The locations of the delaminations along the thicknesswise direction are shown in Fig. 4.

Since the formulation is for two overlapping delaminations, the frequency is approximated by having $a_{2}=5 \times 10^{-5} L$ and $d_{2}=a_{1} / 2$. The axial compressive load is $P_{1}^{0}=0$. The fundamental frequencies of the 'free mode' and 'constrained mode' are shown in Tables $1-3$. A good agreement is obtained between the frequencies predicted by the present solution and the experimental and analytical ('constrained mode') results by Shen and Grady [4] and analytical results by Luo and Hanagud [5]. 
3.2. Verification 2: Buckling of a clamped-clamped beams with a single and double delaminations

The second verification is performed on the buckling of clamped-clamped beams with a single delamination [6] and two delaminations [7,8]. Since the formulation is for two overlapping delaminations, the single delamination is approximated by having by having $a_{2}=5 \times 10^{-5} \mathrm{~L}$ and $d_{2}=a_{1} / 2$ and the two fully overlapping delaminations is approximated by having $a_{1}=a_{2}$ and $d_{2}=5 \times 10^{-5}$ L. Figs. 5 and 6 show the nondimensional 'free mode' frequency $\lambda$ of a beam with a single delamination versus the normalized compressive load $\bar{P}_{1}^{0}$, where

$$
\begin{aligned}
& \lambda^{4}=\frac{\omega^{2} \rho_{1} A_{1}}{D_{1}} L^{4} \\
& \bar{P}_{1}^{0}=\frac{P_{1}^{0}}{P_{c r}}=\frac{P_{1}^{0}}{4 \pi^{2} E I_{1}} L^{2}
\end{aligned}
$$

and where the axial compressive load $P_{1}^{0}$ is normalized with respect to the buckling load of an undelaminated beam $P_{c r}$.

When the 'free mode' frequency is zero $(\lambda=0.0), \bar{P}_{1}^{0}$ corresponds to the buckling load. As shown in Fig. 5, the buckling loads for the beam with a single delamination agree well with the results of Huang and Kardomateas [6] (Table 4). The buckling loads for the beam with two delaminations (Fig. 6) are also shown to agree well with the results of Lim and Parsons [7] and Shu [8] (Table 5). It should be noted that the 'free mode' assumption was used in the above studies on delamination buckling [6-8].

As shown in Table 4 , for $a / L=0.2,0.3,0.4$, the results using the energy method (Lim and Parsons [7]) are lower than the results using an exact solution (Shu [8]). Lim and Parsons' results correspond to the mode 2 buckling load (Fig. 5) resulting in the S-mode shapes. Whereas, Shu's results [8] correspond to the mode 1 buckling load resulting in the 
single hump mode shapes. The solution presented by Lim and Parsons [7] computes for the lowest eigenvalue, and thus, S-mode shapes were observed in their results.

\subsection{Vibration of delaminated composite beam under axial compressive load}

Fig. 7 shows the influence of the normalized compressive load $\bar{P}_{1}^{0}$ on the nondimensional mode 1 frequency $\lambda$ of the simply supported composite beam with two overlapping delamination delaminations. The overlapping delamination is located at $d_{2} / L$ $=a_{1} / 2 L$ and the lengths are $a_{2}=0.2 L$, as shown in Fig. 7 (a), and $2=0.4 L$, as shown in Fig. 7 (b). When the 'free mode' frequency is zero $(\lambda=0.0), \bar{P}_{1}^{0}$ corresponds to the lower bound solution of the buckling load, and when the 'constrained mode' frequency is zero, $\bar{P}_{1}^{0}$ corresponds to the upper bound solution of the buckling load. As shown in Fig. 7, A monotonic relation is observed between the natural frequency $\lambda$ and the compressive load $P_{1}^{0} / P_{d}$, for both 'constrained mode' and 'free mode', $\lambda$ first decreases slowly as $\bar{P}_{1}^{0}$ increases, and then it decreases drastically as $\bar{P}_{1}^{0}$ approaches the buckling load.

Fig. 8 shows the influence of the normalized compressive load $\bar{P}_{1}^{0}$ on the nondimensional mode 1 frequency $\lambda$ of the clamped-clamped composite beam with two overlapping delamination delaminations. The overlapping delamination is located at $d_{2} / L$ $=a_{1} / 2 L$ and the lengths are $a_{2}=0.2 L$, as shown in Fig. 8 (a), and ${ }_{2}=0.4 L$, as shown in Fig. 8 (b). When the 'free mode' frequency is zero $(\lambda=0.0), \bar{P}_{1}^{0}$ corresponds to the lower bound solution of the buckling load, and when the 'constrained mode' frequency is zero, $\bar{P}_{1}^{0}$ corresponds to the upper bound solution of the buckling load. As shown in Fig. 8, for both 'constrained mode' and 'free mode', $\lambda$ first decreases slowly as $\bar{P}_{1}^{0}$ increases, and then it decreases drastically as $\bar{P}_{1}^{0}$ approaches the buckling load. 
The difference between the 'constrained mode' and 'free mode' frequencies increases as $\bar{P}_{1}^{0}$ increases, as shown in Figs. 7 and 8. However, the difference is less significant for simply supported beams (Fig. 7) than clamped-clamped beams (Fig. 8). This difference can be explained by the opening in the 'free mode' mode shapes, as shown in Figs. 9 and 10. The opening increases as the difference between the two frequencies increases. A large opening corresponds to a large difference between the two frequencies, whereas, a small opening corresponds to a small difference. Figs. 9 and 10 also show the influence of the normalized compressive load $\bar{P}_{1}^{0}$ on the 'free mode' mode shape of the beam. It is observed that as $\bar{P}_{1}^{0}$ increases the opening in the 'free mode' mode shape increases. However, the opening is lesser for simply-supported beam than clamped-clamped beam.

Figure 11 and 12 shows the variation of the normalized fundamental frequency raised to the forth power $\left(\lambda / \lambda_{d}\right)^{4}$ with the normalized buckling load $\left(P_{1}{ }^{0} / P_{d}\right)$ for a simply supported beam (Fig 11) and clamped-clamped beam (12). The fundamental frequency raised to the forth power $\lambda^{4}$ is normalized with respect to the frequency of a delaminated beam raised to the forth power $\lambda_{d}^{4}$, while the normalized compressive load $P_{1}{ }^{0}$ is normalized with respect to the buckling load of the delaminated beam $P_{d}$. It should be noted that the term $\left(\lambda / \lambda_{d}\right)^{4}$ has the same value as $\left(\omega / \omega_{d}\right)^{2}$, which was used in Amba-Rao [36] and Galef [37]. The delamination length $a_{1} / L$ varies from 0.3 to 0.7 for delamination length $a_{2} / L=0.2$, and $a_{1} / L$ varies from 0.3 to 0.5 for $a_{2} / L=0.4$ It can be seen that the relation between $\left(\lambda / \lambda_{d}\right)^{4}$ and $\left(P_{1}^{0} / P_{d}\right)$ can be expressed as $\left(\lambda / \lambda_{d}\right)^{4}=1-$ $P_{1}^{0} / P_{d}$, which is identical in form to that of an undelaminated beam, as shown in Eq. (1).

The results for a clamped-clamped beam are shown in Fig. 12. It can be seen that the variation of the square of the normalized fundamental frequency $\left(\lambda / \lambda_{d}\right)^{4}$ (Fig. 12) with the normalized compressive load $P_{1}{ }^{0} / P_{d}$ becomes nonlinear as the delamination length $a_{1} / L$ 
increases. However, the equation $\left(\lambda / \lambda_{d}\right)^{4}=1-P_{1}^{0} / P_{d}$ can roughly describe the relation between $\left(\lambda / \lambda_{d}\right)^{4}$ and $P_{1}^{0} / P_{d}$ for the 'constrained mode' frequencies, as shown in Fig.12 (a). For the 'free mode', the relationship becomes non-linear owing to the large opening observes in the 'free mode' modeshapes, as shown in Fig.12 (b).

\section{Conclusions}

Analytical solutions have been developed to study free vibrations of an axially loaded composite beam with two overlapping delaminations. The delaminated beam was analyzed as seven interconnected Euler-Bernoulli beams and the continuity and boundary conditions were satisfied between adjoining beams. Both the 'free mode' and the 'constrained mode' assumption in the study of buckling and vibration of delaminated laminates were used. These analytical solutions can also be used to analyze pure buckling and pure vibration problems. Based on the study, the following conclusions can be drawn:

1. For both simply supported and clampled-clamped composite beams, the natural frequency decreases with increasing axial compressive loads, which drastically decreases as the compressive load approaches the buckling load.

2. For simply supported beams, the square of the 'constrained mode' and 'free mode' frequencies varies linearly with the axial compressive load. Thus, once the natural frequency and the buckling load of the delaminated beam are identified, an estimate of the natural frequency of the delaminated beam under axial compressive loading can be obtained.

3. For clamped-clamped beams, a linear relation can roughly describe the relation between the square of the 'constrained mode' frequency and the axial compressive load. A non-linear relation is observed between the square of the 'free mode' 
frequency and the axial compressive load due to the large opening between the delaminated layers in the 'free mode' modeshape.

\section{References}

1. Della CN, Shu D. Vibration of delaminated composite laminates: A review. Appl Mech Rev 2007; 60(1):1-20.

2. Wang JTS, Liu YY, Gibby JA. Vibration of split beams. J Sound Vib 1982;84(4): 491-502.

3. Mujumdar PM, Suryanarayan S. Flexural vibrations of beams with delaminations. J Sound Vib 1982;125(3):441-461.

4. Shen MH, Grady JE. Free Vibrations of delaminated beams. AIAA J 1992;30(5):1361-1370.

5. Luo H, Hanagud S. Dynamics of delaminated beams. Int J Solids Struct 2000;37(10):1501-1519.

6. Huang H, Kardomateas GA. Buckling of orthotropic beam-pates with multiple central delaminations. Int J Sol Struct 1998;35(13):1355-1362.

7. Lim YB, Parsons ID. The linearized buckling analysis of a composite beam with multiple delaminations, Int J Sol Struct 1992;30(22):3085-3099.

8. Shu D. Buckling of multiple delaminated beams. Int J Sol Struct 1988;35(13):14511465.

9. Wang JTS, Lin CC. Engineering analysis of buckling of delaminated beam plates. Compos Struct 1996;34(4):397-407.

10. Wang JTS, Pu HN, Lin CC. Buckling of beam-plates having multiple delaminations. J Compos Mater 1997;31(10);1002-1025. 
11. Parlapalli MSR, Sylvain D, Shu D, Della CN (2004). Buckling analysis of tri-layer beams with multiple separated delaminations. Compos Struct 2004;66(1-4):53-60.

12. Cappello F, Tumino D. Numerical analysis of composite plates with multiple delaminations subjected to uniaxial buckling load. Compos Sci Tech 2006;66(2):264272.

13. Parlapalli MSR, Shu D. Buckling of composite beams with two non-overlapping delaminations: Lower and Upper bounds. Int J Mech Sci 2007;49(7):793-805.

14. Parlapalli MSR, Shu D, Chai GB. Buckling of composite beams with two enveloped delaminations: Lower and upper bounds. Comput Struct 2008;86(23-24):2155-2165

15. Shu D. Vibration of sandwich beams with double delaminations. Compos Sci Tech 1995;54(1):101-109.

16. Della CN, Shu D. Vibration of beams with double delaminations. J Sound Vib 2005; 282(3-5):919-935.

17. Lestari W, Hanagud S. Health monitoring of structures: multiple delamination dynamics in composite beams. In: Proceedings of the $40^{\text {th }}$ AIAA/ASME/ASCE/AHS/ASC Structures, Structural Dynamics and Materials Conference and Adaptive Structures Forum, St. Louis, MO, April 1999.

18. Lee S, Park T, Voyiadjis GZ. Vibration analysis of multi-delaminated beams. Compos: Part B 2003;34(7):647-659.

19. Shu D, Della CN. Free vibration analysis of composite beams with two nonoverlapping delaminations. Int J Mech Sci 2004;46(4):509-526.

20. Shu D, Della CN. Vibrations of multiple delaminated beams. Compos Struc 2004; 64(3-4):467-477.

21. Della CN, Shu D. Free vibration analysis of composite beams with overlapping delaminations. Eur J Mech A-Solid 2005;24(3):491-503. 
22. Ju F, Lee HP, Lee KH. Free-vibration analysis of composite beams with multiple delaminations. Compos Eng 1994;4(7):715-730.

23. Ju F, Lee HP, Lee KH. Finite element analysis of free vibration of delaminated composite plates. Compos Eng 1995;5(2):195-209.

24. Chen H-P. Free vibration of prebuckled and postbuckled plates with delamination. Compos Sci Tech 1994;51(3): 451-462.

25. Chen H-P, Tracy JJ, Nonato R. Vibration analysis of delaminated composite laminates in prebuckled states based on a new constrained model. J Compos Mater $1995 ; 29(2): 229-256$.

26. Chang TP, Hu CY, Jane KC. Vibration of delaminated composite plates under axial load. Mech Struc Mach 1998; 26(2):195-218.

27. Yin W-L, Jane KC. Vibration of a delaminated beam-plate relative to buckled states. J Sound Vib 1992;156(1):125-140.

28. Jane KC, Chen CC. Postbuckling deformation and vibration of a delaminated beamplate with arbitrary delamination location. Mech Res Comm 1998;25(3):337-351.

29. Chang T-P, Liang J-Y. Vibration of postbuckled delaminated beam plates. Int J Sol Struct 1998;35(12):1199-1217.

30. Chen H-P, Goggin PJ. Vibration of a delaminated beam-plate relative to postbuckling states with shear deformation theory. J Sound Vib 1994;176(2):163-178.

31. Lu X, Hanagud S. Health monitoring of structures: multiple delamination dynamics in composite beams with axial loads. In: Proceedings of the $40^{\text {th }}$ AIAA/ASME/ASCE/AHS/ASC Structures, Structural Dynamics and Materials Conference, St. Louis, MO, April 12-15, 1999. p. 2348-2357.

32. Jane KC, Harn YC. Vibration of delaminated beam-plates with multiple delaminations under axial forces. Mech Struc Mach 2000;28(1): 49-64. 
33. Lee S, Park T, Voyiadjis GZ. Free vibration analysis of axially compressed laminated composite beam-columns with multiple delaminations. Compos: Part B 2002;33(8): 605-617.

34. Della CN, Shu D. Vibration of beams with two overlapping delaminations in prebuckled states. Compos: Part B 2007;38(2):109-118.

35. Della CN, Shu D. Free vibration analysis of multiple delaminated beams under axial compressive load. J Reinf Plast Compos 2009; 28(11):1365-1381.

36. Amba-Rao CL. Effect of end conditions on the lateral frequencies of uniform straight columns. J Acoust Soc Am 1967;42(2);900-901.

37. Galef AE. Bending frequencies of compressed beams. J Acoust Soc Am 1968;44(2):643.

38. Bokaian A. Natural frequencies of beams under compressive axial loads. J Sound Vib 1988;126(1):49-65.

39. Jones RM. Mechanics of composite materials, $2^{\text {nd }}$ ed. Taylor and Francis Inc., Philadelphia, 1999. 


\section{Figure captions}

Figure 1. A beam with two overlapping delaminations under axial compressive loads.

Figure 2. The $i$-th beam laminate.

Figure 3. The vibration configuration between $x=x_{2}$ and $x=x_{5}$. The lengths of the central lines remain unchanged.

Figure 4. Interface locations of the delaminations for a $[0 / 90]_{2 S}$ Graphite/Epoxy composite laminate (Shen and Grady, 1992).

Figure 5. The mode 1 'free mode' frequency $\lambda$ versus the axial compressive load $P_{1}^{0} / P_{c r}$ for a homogeneous clamped-clamped beam with a single delamination, $d / L=0.0$. When $\lambda=0, P_{1}^{0} / P_{c r}$ is the buckling load: (a) $H_{2}=0.2 H_{1}$; (b) $H_{2}=0.3 H_{1}$.

Figure 6 . The mode 1 and mode 2 'free mode' frequencies versus the axial compressive load $P_{1}^{0} / P_{c r}$ for a homogeneous clamped-clamped beam with double delaminations, $d / L=0.0$. Mode 2 buckling loads are lower than the mode 1 buckling loads for $a / L=0.2,0.3,0.4$.

Figure 7. Influence of the axial compressive load $P_{1}^{0} / P_{c r}$ on the mode 1 frequency $\lambda$ of a simply-supported composite beam with two overlapping delaminations, $d_{1} / L=0.0$. When $\lambda=0, P_{1}^{0} / P_{c r}$ is equal to the normalized buckling load: (a) $a_{2} / L=0.2$; (b) $a_{2} / L=0.4$.

Figure 8. Influence of the axial compressive load $P_{1}^{0} / P_{c r}$ on the mode 1 frequency $\lambda$ of a clamped-clamped composite beam with two overlapping delaminations, $d_{1} / L=0.0$.

When $\lambda=0, P_{1}^{0} / P_{c r}$ is equal to the normalized buckling load: (a) $a_{2} / L=0.2$; (b) $a_{2} / L=0.4$.

Figure 9. 'Free mode' mode shapes of a simply supported composite beam with two overlapping delaminations with $H_{2}=H_{3}=0.25 H_{1}$.

Figure10. 'Free mode' mode shapes of a clamped-clamped composite beam with two overlapping delaminations with $H_{2}=H_{3}=0.25 H_{1}$.

Figure 11. Variation of the square of the normalized mode 1 frequency $\left(\lambda / \lambda_{d}\right)^{4}$ of a simply supported beam with normalized compressive load $P_{1}^{0} / P_{d}$ for various delamination lengths with $H_{2}=H_{3}=0.25 H_{1}$ and $d_{1} / L=0.0$ for both 'Constrained mode' and 'Free mode'.

Figure 12. Variation of the square of the normalized mode 1 frequency $\left(\lambda / \lambda_{d}\right)^{4}$ of a simply supported beam with normalized compressive load $P_{1}^{0} / P_{d}$ for various delamination lengths with $H_{2}=H_{3}=0.25 H_{1}$ and $d_{1} / L=0$ : (a) 'Constrained mode' ; (b) 'Free mode'. 



Figure 1

Della CN 


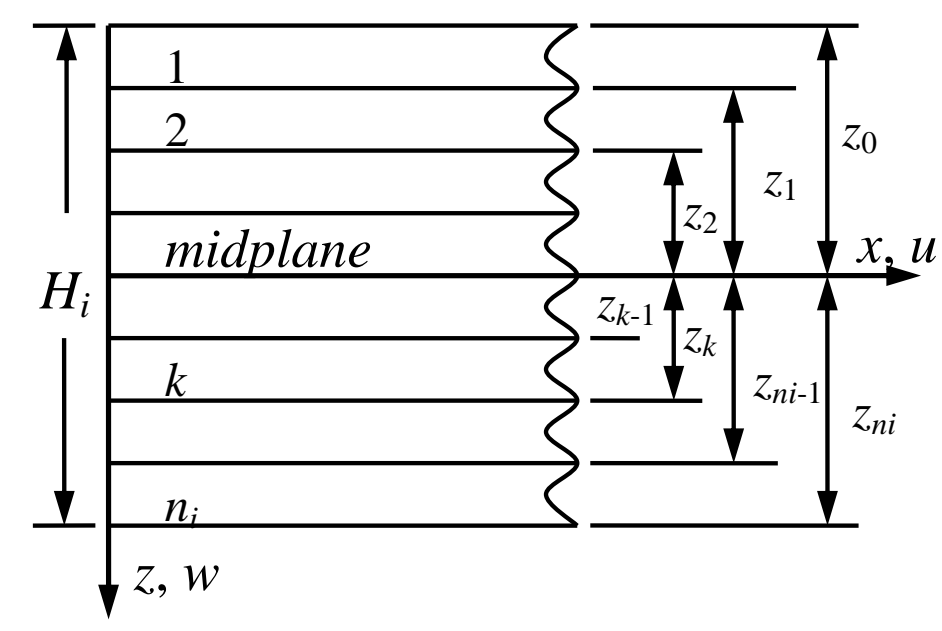

Figure 2. The $i$-th beam laminate.

Della CN 


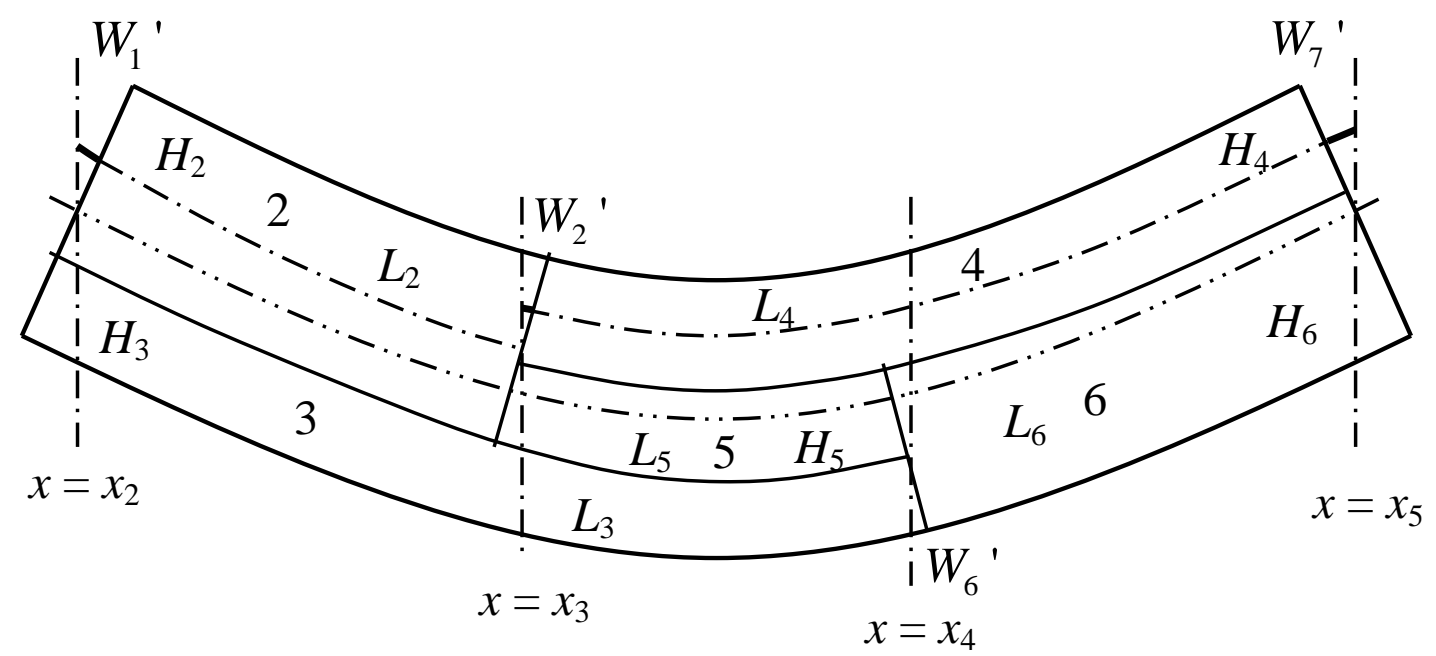

Figure 3

Della CN 


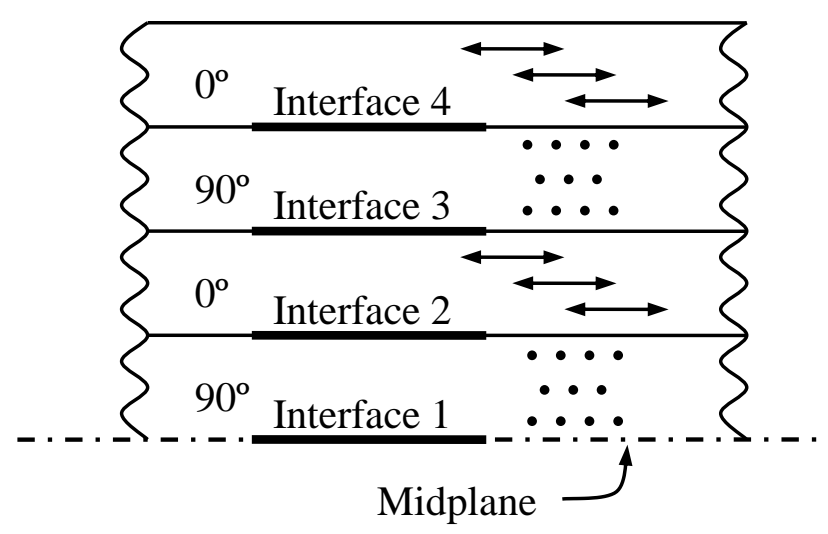

Figure 4

Della CN 


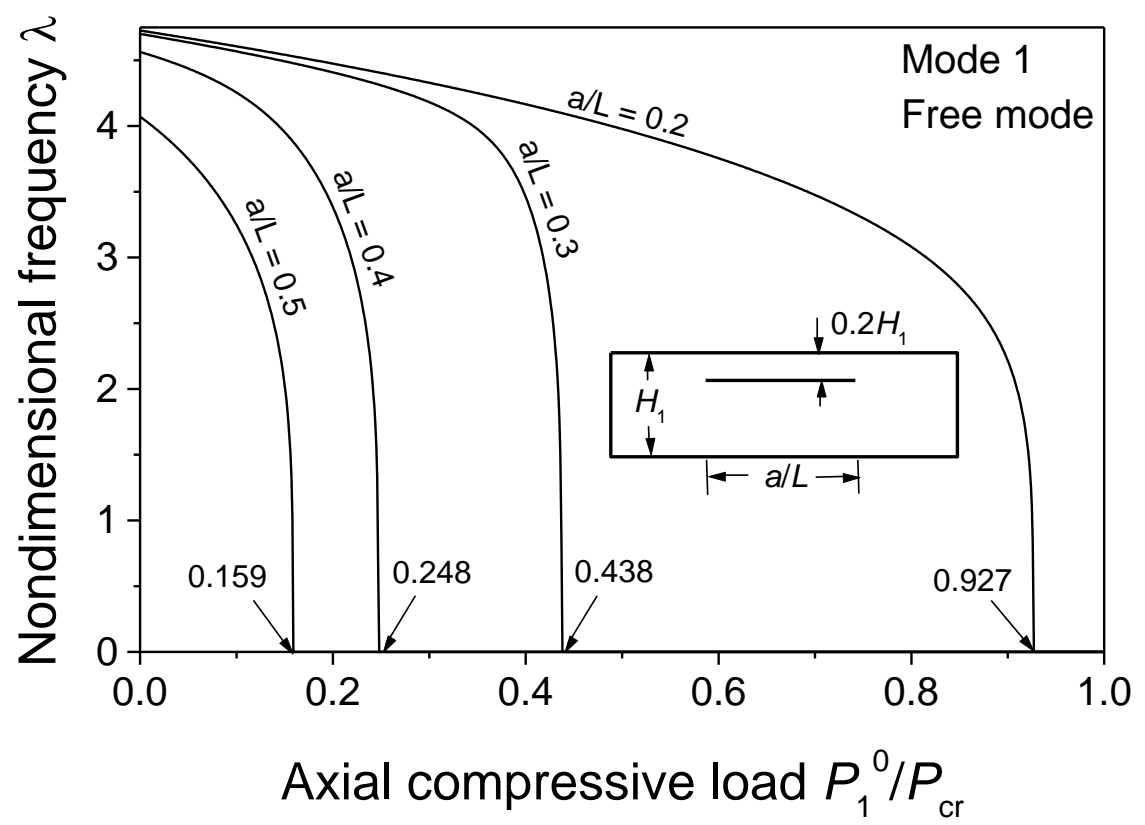

(a)

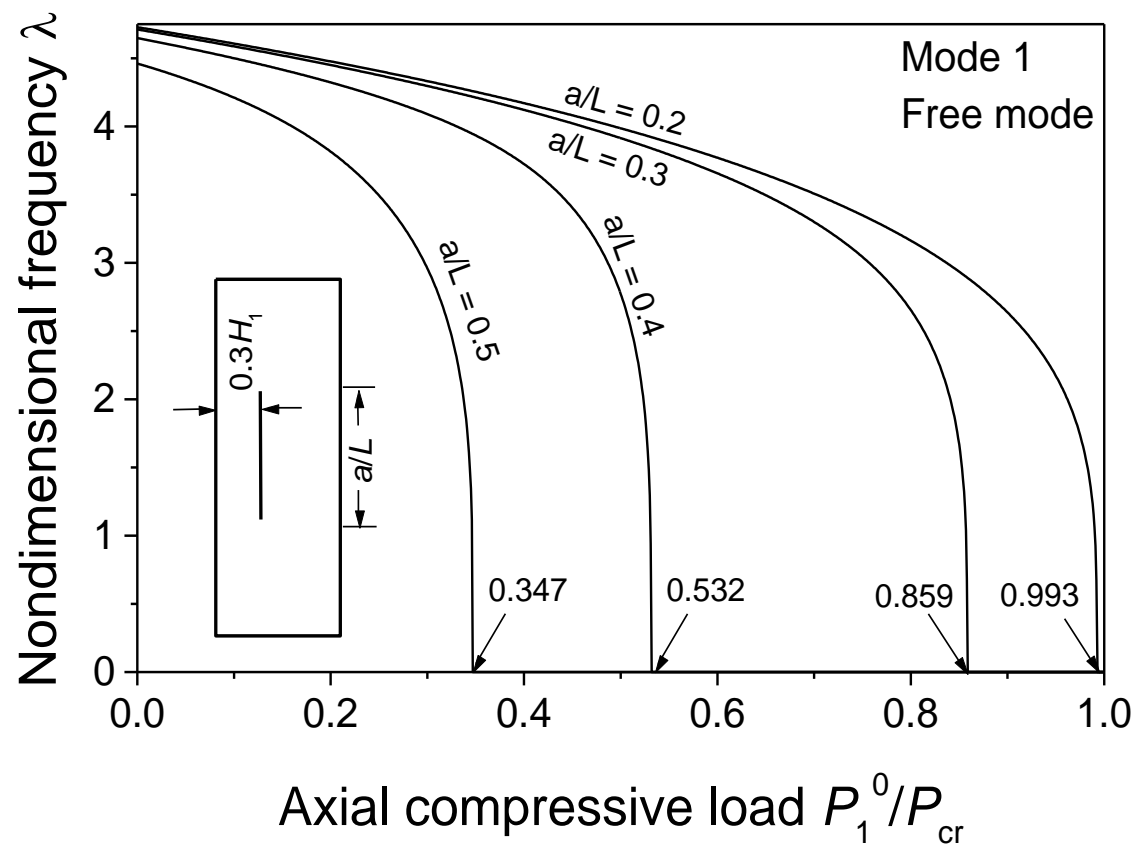

(b)

Figure 5

Della CN 


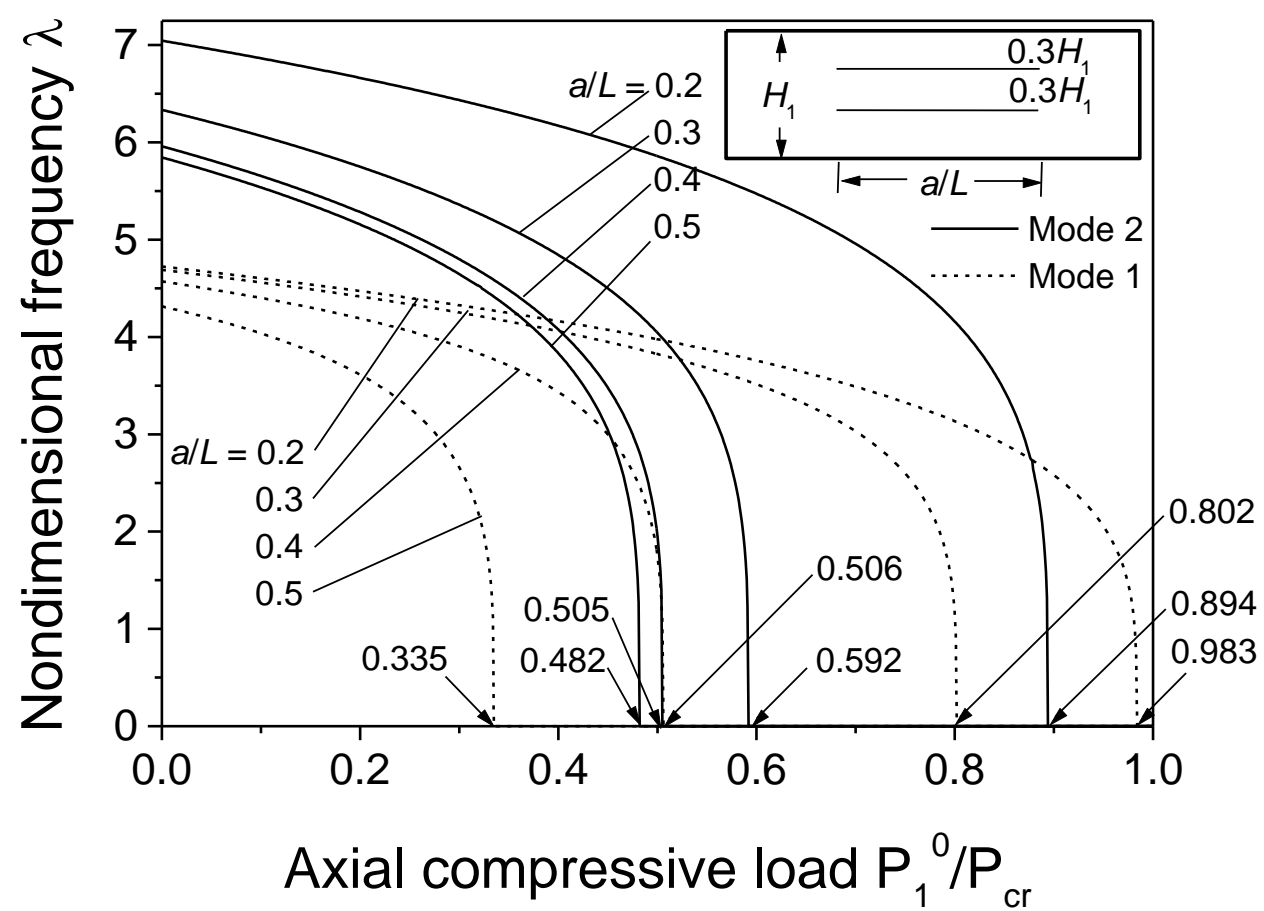

Figure 6

Della CN 


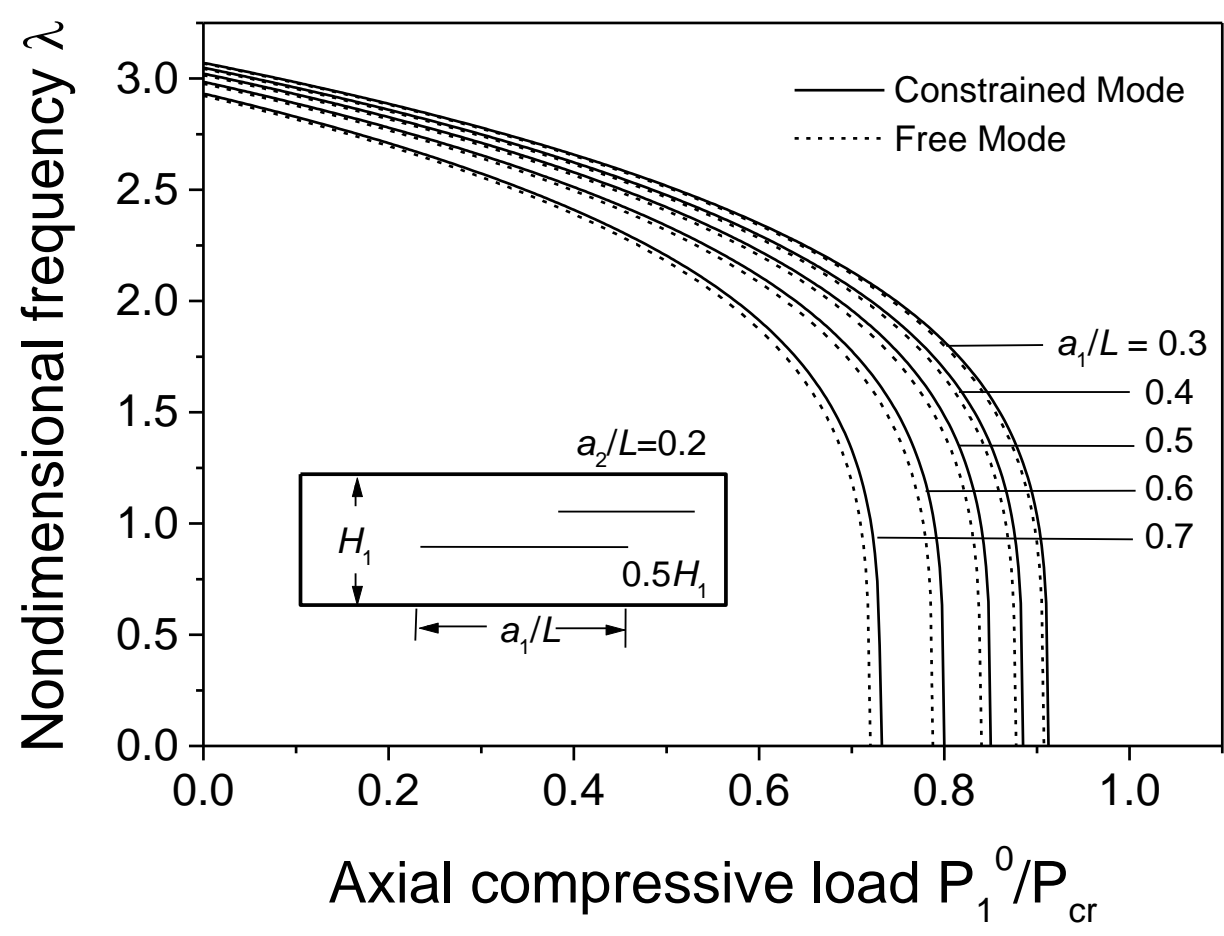

(a)

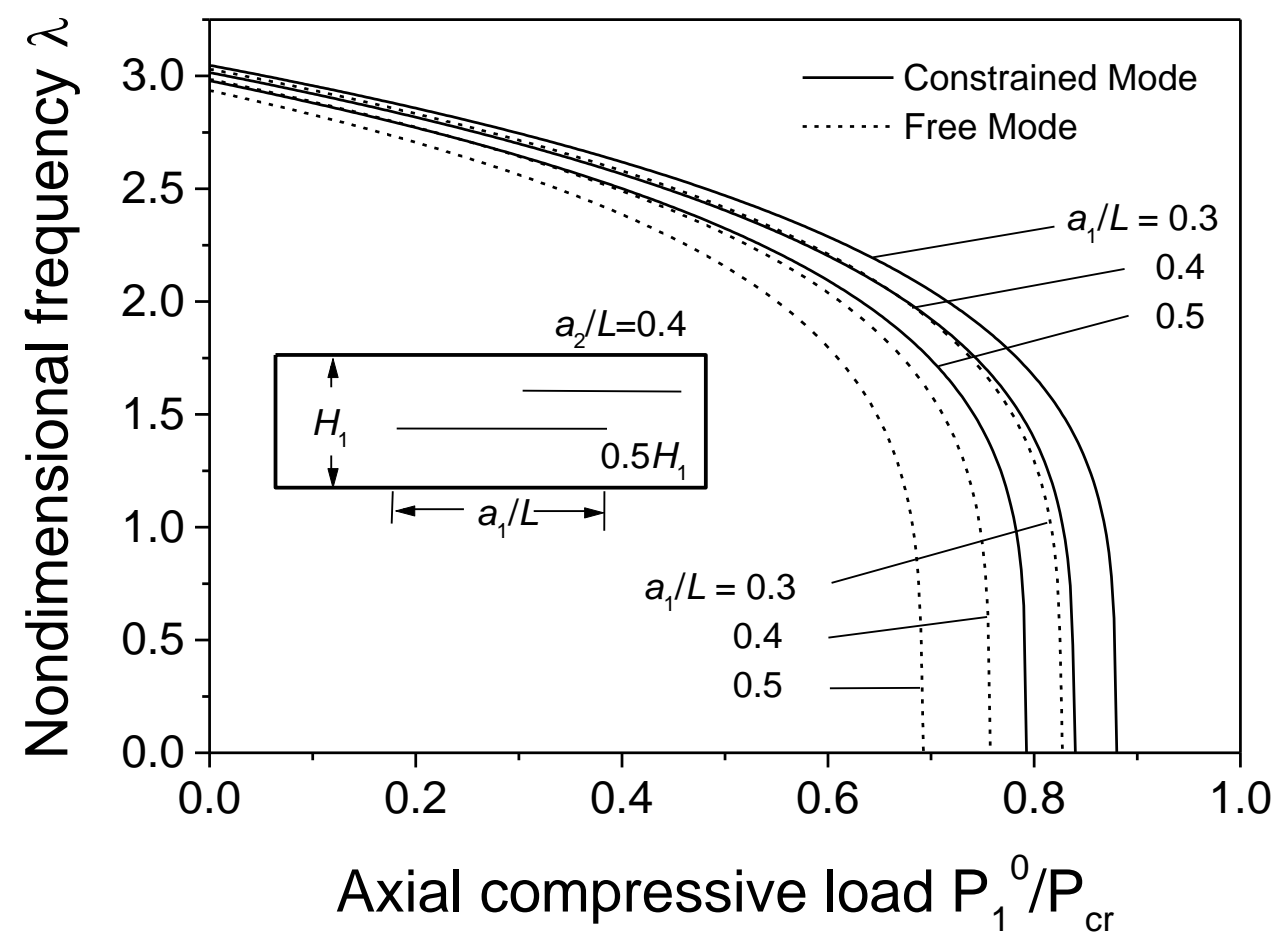

Figure 7

(b)

Della CN 


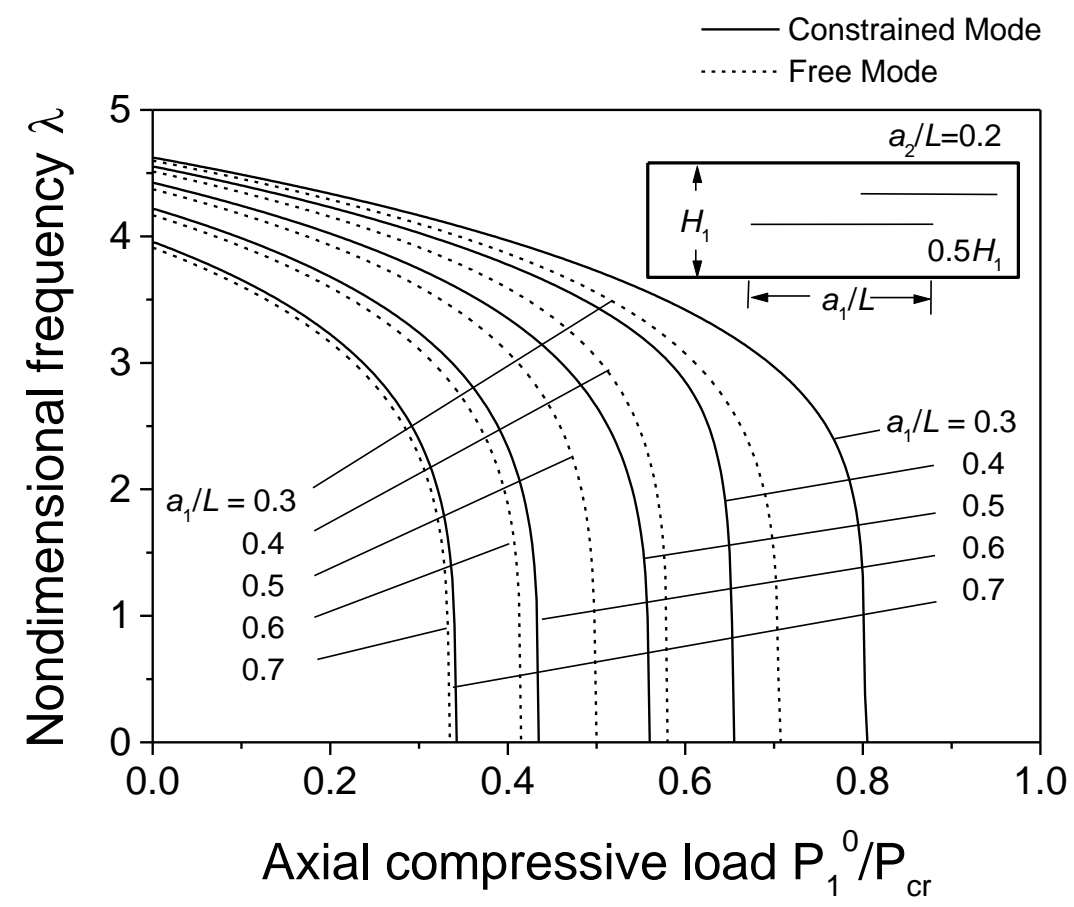

(a)

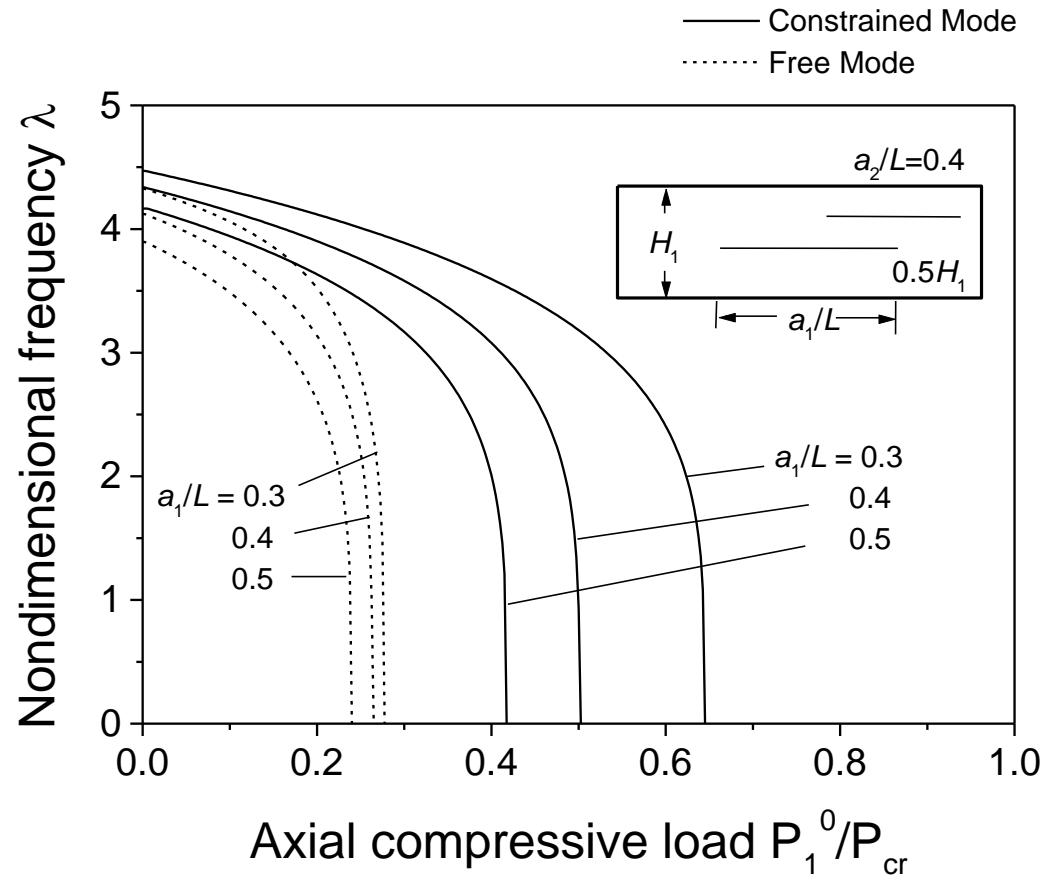

(b)

Figure 8.

Della CN 

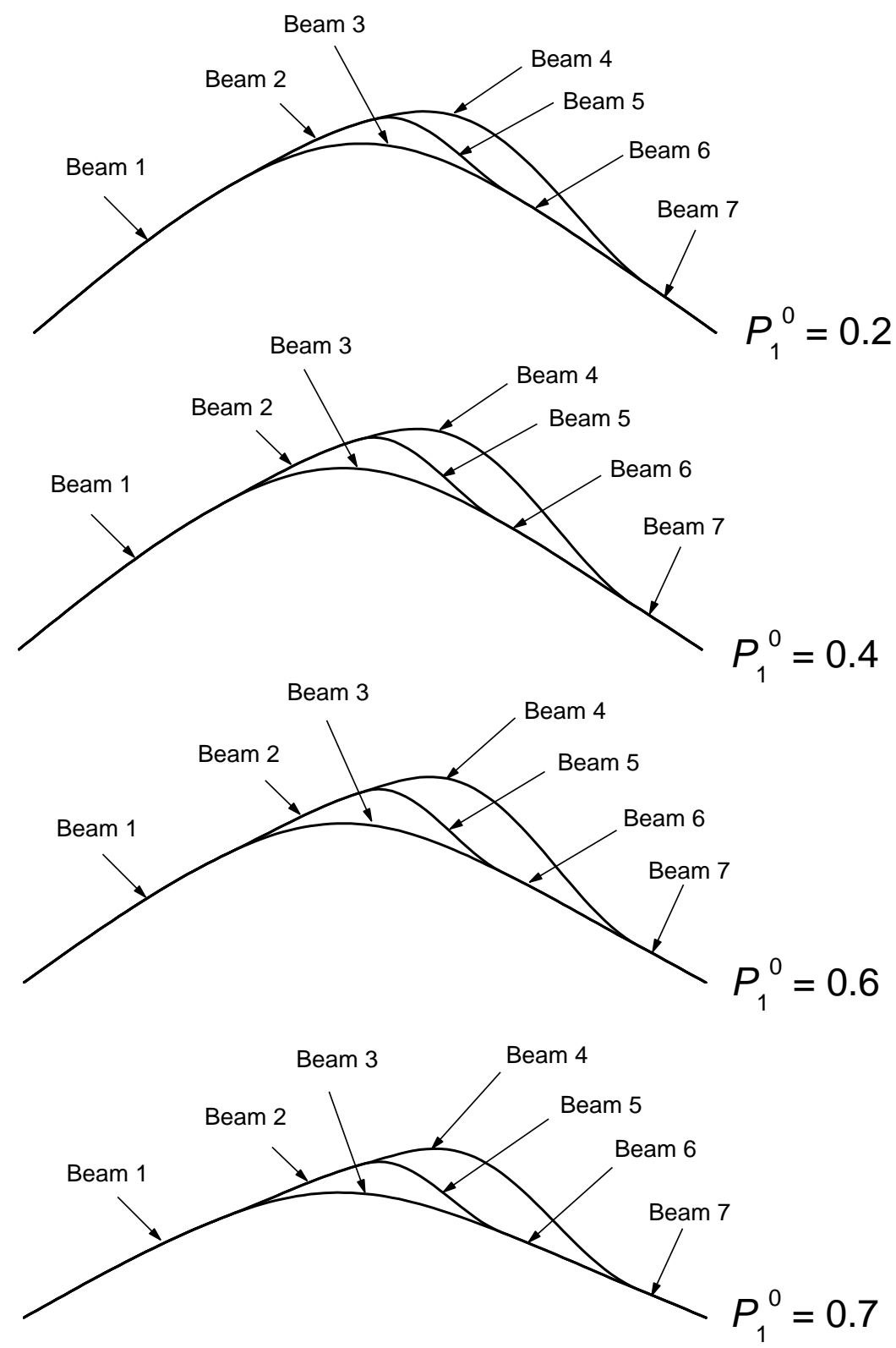

Figure 9

Della CN 

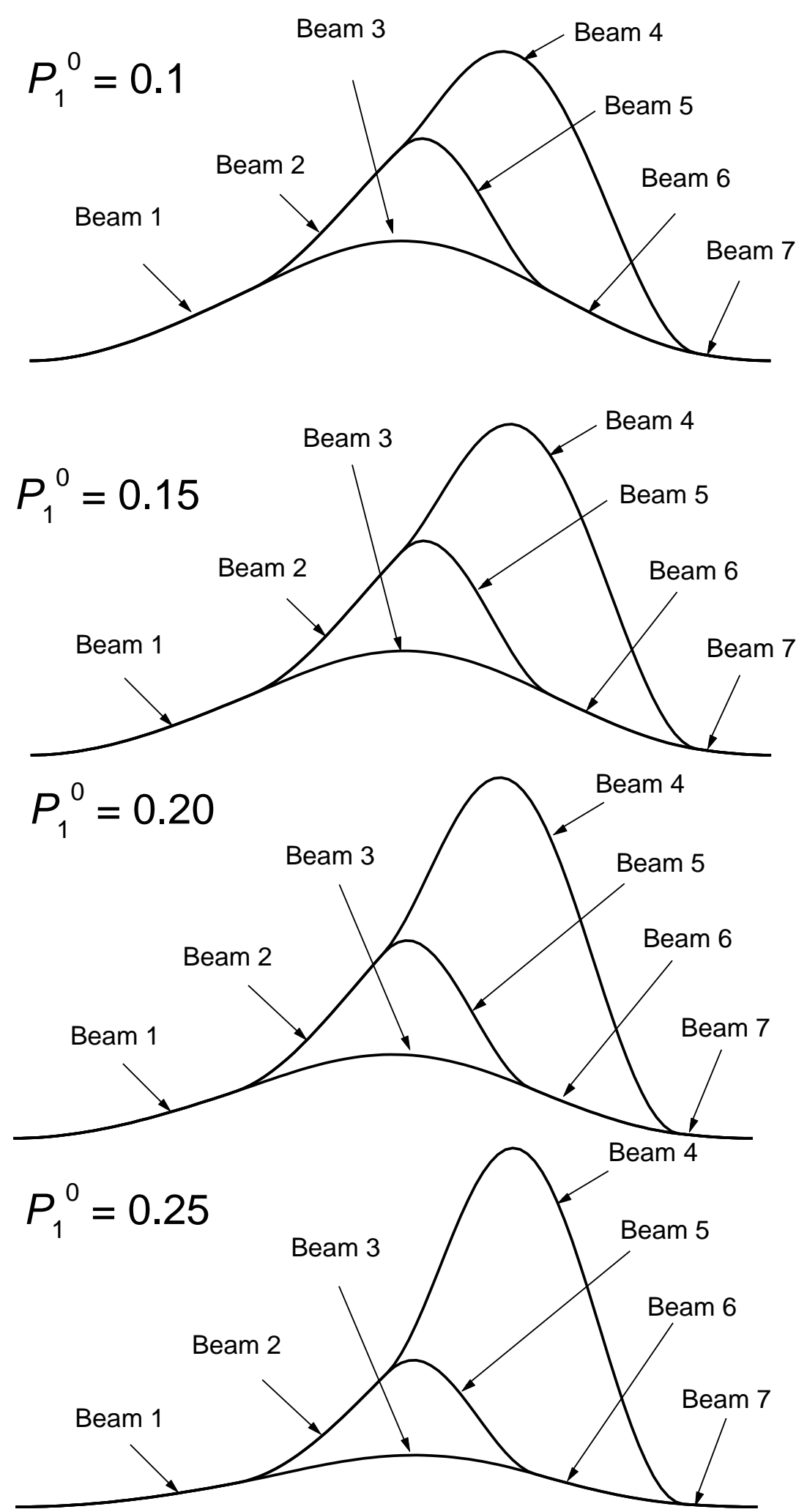

Figure 10 Della CN 


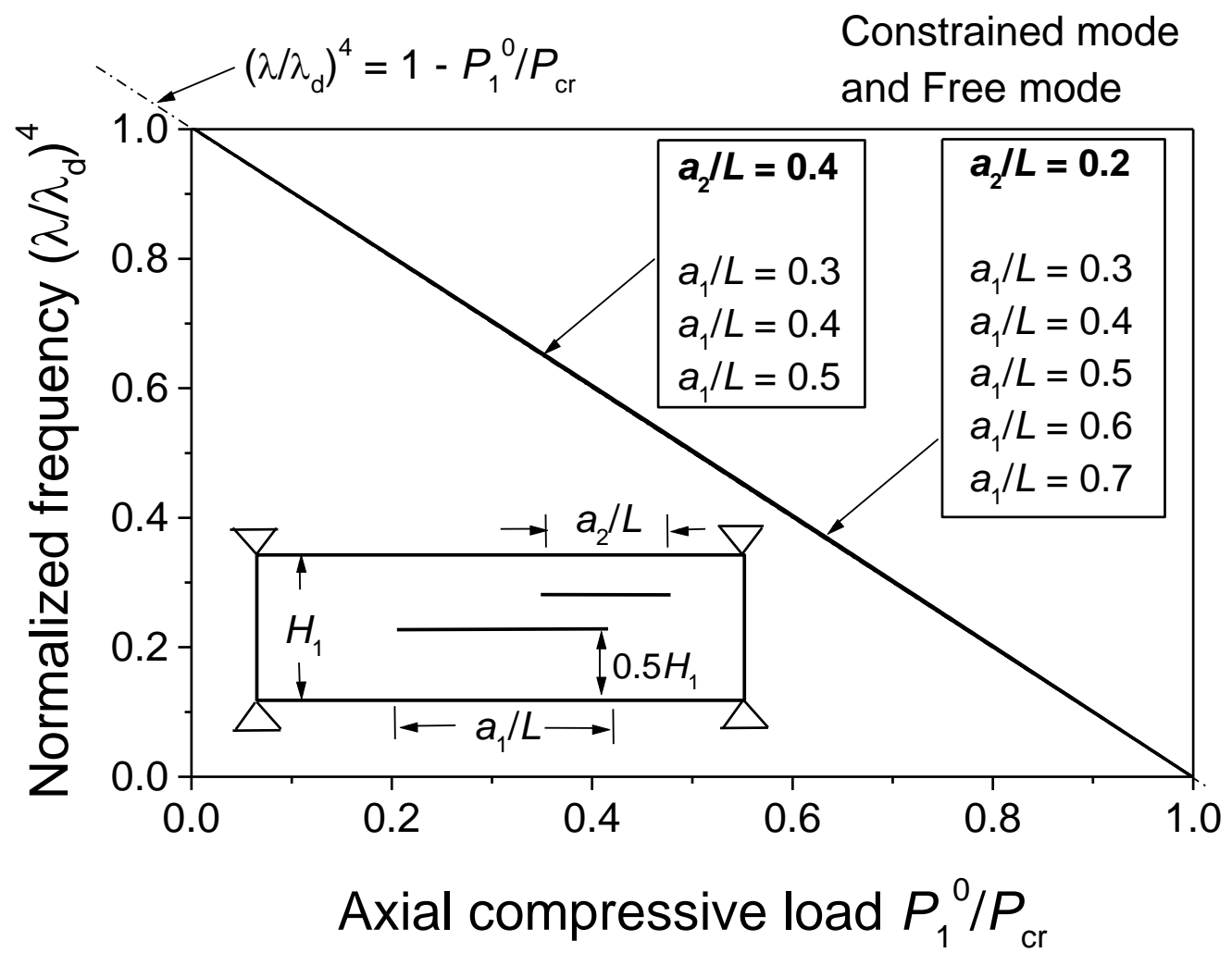

Figure 11

Della CN 


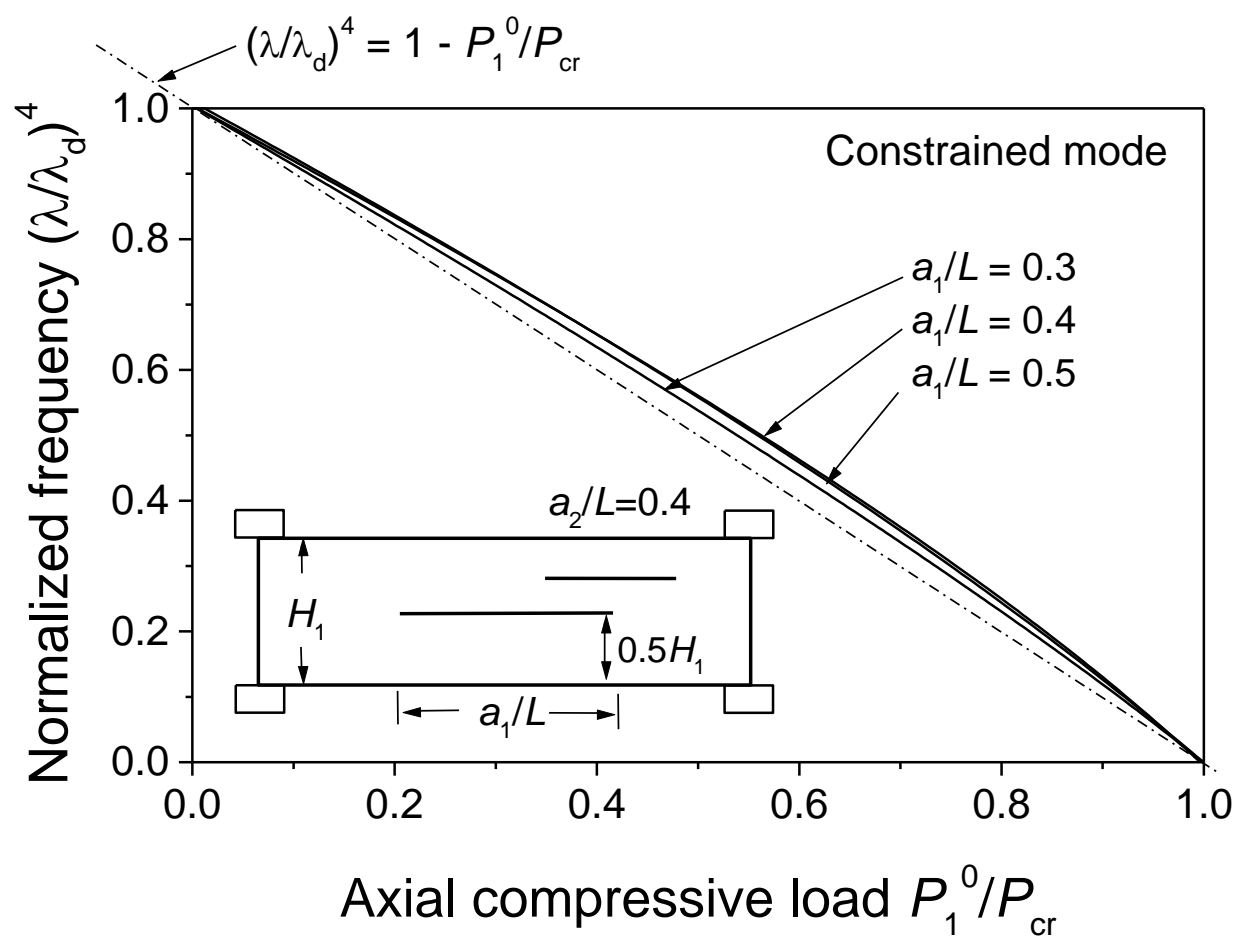

(a)

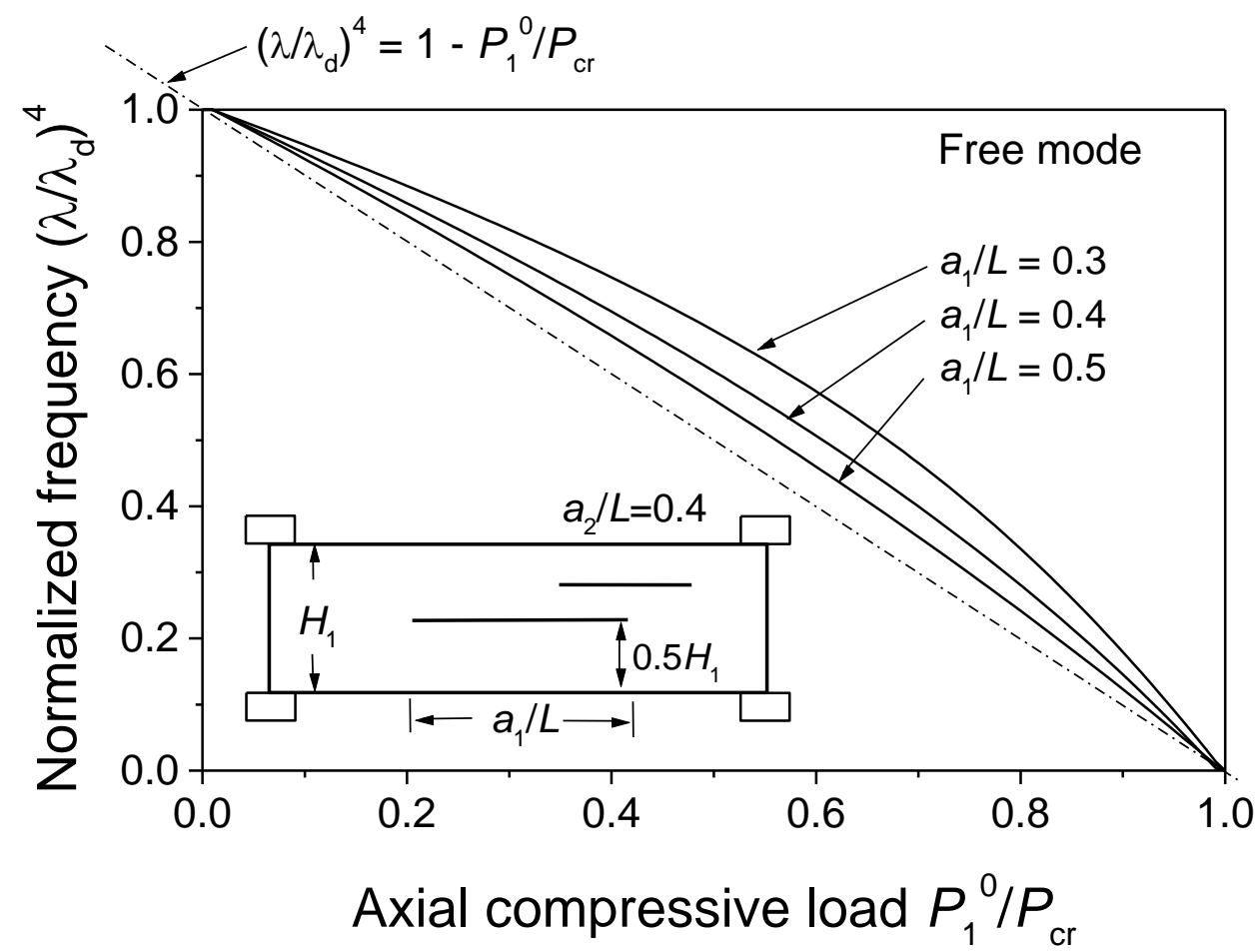

(b)

Figure 12

Della CN 


\section{Table 1}

Interface 1 frequencies $(\mathrm{Hz})$

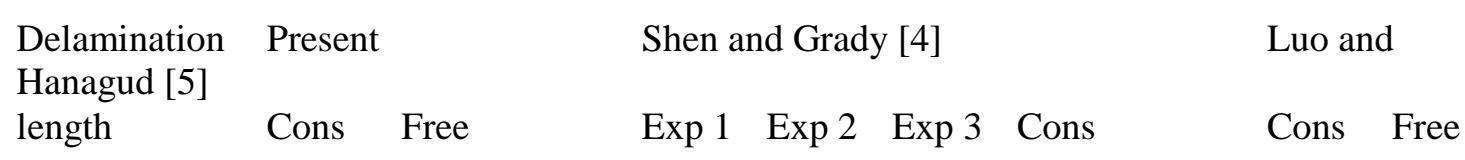

\begin{tabular}{llllllllll}
\hline Intact & 81.88 & 81.88 & 79.88 & 79.88 & 79.75 & 82.04 & 81.86 & 81.86 \\
& & & & & & & & & \\
$25.4 \mathrm{~mm}$ & 80.47 & 80.47 & 78.38 & 79.13 & 77.00 & 80.13 & 81.84 & 81.84 \\
$50.8 \mathrm{~mm}$ & 75.36 & 75.36 & 74.38 & 75.00 & 76.75 & 75.29 & 76.81 & 76.81 \\
& & & & & & & & \\
$76.2 \mathrm{~mm}$ & 66.14 & 66.13 & 68.25 & 66.25 & 66.38 & 66.94 & 67.64 & 67.64 \\
$101.6 \mathrm{~mm}$ & 55.67 & 55.67 & 57.62 & 57.50 & 57.50 & 57.24 & 56.95 & 56.95
\end{tabular}

Table 2

Interface 2 frequencies ( $\mathrm{Hz})$

\begin{tabular}{|c|c|c|c|c|c|c|c|c|}
\hline \multirow{2}{*}{$\begin{array}{l}\text { Delamination } \\
\text { Hanagud [5] } \\
\text { length }\end{array}$} & \multicolumn{2}{|c|}{ Present $^{\mathrm{b}}$} & \multicolumn{4}{|c|}{ Shen and Grady [4] } & \multicolumn{2}{|c|}{ Luo and } \\
\hline & Cons & Free & $\operatorname{Exp} 1$ & $\operatorname{Exp} 2$ & Exp 3 & Cons & Cons & Free \\
\hline Intact & 81.88 & 81.88 & 79.88 & 79.88 & 79.75 & 82.04 & 81.86 & 81.86 \\
\hline $25.4 \mathrm{~mm}$ & 80.58 & 80.58 & 78.38 & 78.38 & 76.63 & 81.39 & 80.86 & 80.86 \\
\hline $50.8 \mathrm{~mm}$ & 75.81 & 75.81 & 75.13 & 75.25 & 75.00 & 78.10 & 76.62 & 76.62 \\
\hline $76.2 \mathrm{~mm}$ & 67.05 & 67.05 & 64.00 & 70.00 & 69.88 & 71.16 & 68.80 & 68.80 \\
\hline $101.6 \mathrm{~mm}$ & 56.86 & 56.86 & 45.75 & 49.75 & 49.50 & 62.12 & 59.34 & 59.34 \\
\hline
\end{tabular}

Table 3

Interface 3 frequencies (Hz)

\begin{tabular}{|c|c|c|c|c|}
\hline Delamination & Present $^{\mathrm{b}}$ & Shen and Grady [4] & & Luo and \\
\hline length & Free & $\operatorname{Exp} 1 \quad \operatorname{Exp} 2 \operatorname{Exp} 3$ & Cons & Cons Free \\
\hline
\end{tabular}




\begin{tabular}{|c|c|c|c|c|c|c|c|c|}
\hline Intact & 81.88 & 81.88 & 79.88 & 79.88 & 79.75 & 82.04 & 81.86 & 81.86 \\
\hline $25.4 \mathrm{~mm}$ & 81.53 & 81.53 & 79.63 & 80.13 & 80.63 & 81.46 & 82.02 & 82.01 \\
\hline $50.8 \mathrm{~mm}$ & 80.13 & 80.09 & 79.50 & 81.88 & 77.88 & 79.93 & 80.79 & 80.74 \\
\hline $76.2 \mathrm{~mm}$ & 77.03 & 76.75 & 75.63 & 77.13 & 78.13 & 76.71 & 77.82 & 77.52 \\
\hline $101.6 \mathrm{~mm}$ & 72.28 & 70.92 & 73.38 & 73.63 & 70.38 & 71.66 & 73.15 & 71.73 \\
\hline
\end{tabular}

\section{Table 4}

Normalized buckling loads for clamped-clamped beams with a single delamination [6].

Delamination $\quad H_{2}=0.2 H_{1} \quad H_{2}=0.3 H_{1}$

length, a/L

$\begin{array}{lll}0.20 & 0.927 & 0.992 \\ 0.30 & 0.437 & 0.858 \\ 0.40 & 0.247 & 0.531 \\ 0.50 & 0.159 & 0.347\end{array}$

Table 5

Normalized buckling loads for clamped-clamped beams with two delaminations, $H_{2}=H_{3}=0.3 H_{1}, H_{4}=0.4 H_{1}$.

\begin{tabular}{lll}
\hline $\begin{array}{l}\text { Delamination } \\
\text { length, a/L }\end{array}$ & $\begin{array}{l}\text { Energy } \\
\text { method [7] }\end{array}$ & $\begin{array}{l}\text { Exact } \\
\text { solution[8] }\end{array}$ \\
\hline & & \\
0.20 & 0.894 & 0.984 \\
0.30 & 0.592 & 0.802 \\
0.40 & 0.505 & 0.506 \\
0.50 & 0.335 & 0.237 \\
\hline
\end{tabular}

